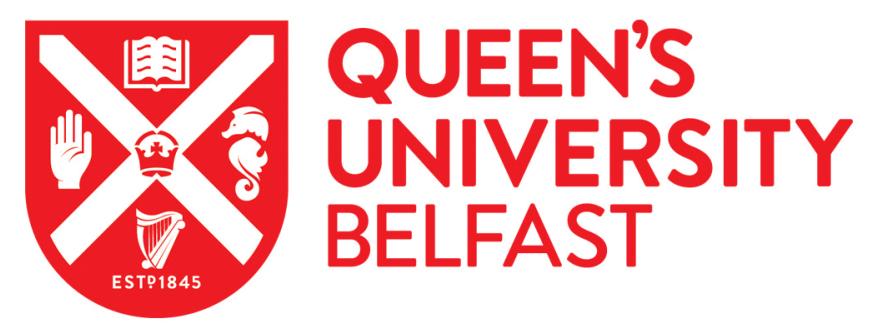

\title{
Corrosion resistance of self-growing TiC coating on SIMP steel in LBE at $600^{\circ} \mathrm{C}$
}

Shi, Q. -Q., Yan, W., Sha, W., Wang, W., Shan, Y. -Y., \& Yang, K. (2016). Corrosion resistance of self-growing TiC coating on SIMP steel in LBE at $600^{\circ} \mathrm{C}$. Materials and Corrosion, 67(11), 1204-1212.

https://doi.org/10.1002/maco.201508727

Published in:

Materials and Corrosion

Document Version:

Peer reviewed version

Queen's University Belfast - Research Portal:

Link to publication record in Queen's University Belfast Research Portal

Publisher rights

(c) 2016 WILEY-VCH Verlag GmbH \& Co. KGaA, Weinheim.

This is the peer reviewed version of this article, which has been published in final form at DOI: $10.1002 /$ maco.201508727. This article may be used for non-commercial purposes in accordance with Wiley Terms and Conditions for Self-Archiving.

\section{General rights}

Copyright for the publications made accessible via the Queen's University Belfast Research Portal is retained by the author(s) and / or other copyright owners and it is a condition of accessing these publications that users recognise and abide by the legal requirements associated with these rights.

Take down policy

The Research Portal is Queen's institutional repository that provides access to Queen's research output. Every effort has been made to ensure that content in the Research Portal does not infringe any person's rights, or applicable UK laws. If you discover content in the Research Portal that you believe breaches copyright or violates any law, please contact openaccess@qub.ac.uk. 


\title{
Corrosion resistance of self-growing TiC coating on SIMP steel in $\mathrm{LBE}$ at $600{ }^{\circ} \mathrm{C}$
}

\author{
Quanqiang Shi ${ }^{a, b}$, Wei Yan ${ }^{a, *}$, Wei Sha ${ }^{c}$, Wei Wanga, Yiyin Shana ${ }^{a}$ Ke Yang ${ }^{a}$ \\ ${ }^{a}$ Key Laboratory of Nuclear Materials and Safety Assessment, Institute of Metal Research, \\ Chinese Academy of Sciences, Shenyang 110016, China \\ ${ }^{b}$ University of Chinese Academy of Sciences, Beijing 100049, China

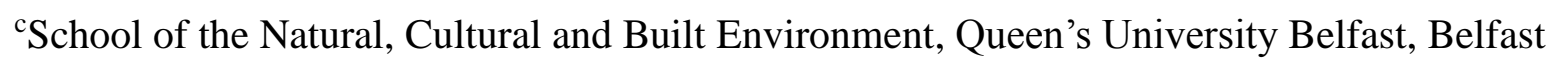 \\ BT9 5AG, UK
}

*Corresponding author. Tel.: +86 24 83978745; fax: +86 2483978745

E-mail address: weiyan@imr.ac.cn

\begin{abstract}
SIMP steel was newly developed as a candidate structural material for the accelerator driven subcritical system. The serious decarburization of SIMP steel because of the high Si content was used to successfully form a self-growing TiC coating on the surface, after the Ti deposition as a first step. This TiC layer can effectively protect the surface from the static liquid lead-bismuth eutectic (LBE) corrosion at $600{ }^{\circ} \mathrm{C}$ up to $2000 \mathrm{~h}$ in the low oxygen LBE. However, in the oxygen saturated $\mathrm{LBE}$, the $\mathrm{TiC}$ coating is oxidized into porous $\mathrm{TiO}_{2}$ after only $500 \mathrm{~h}$ and fails to protect. Therefore, the self-growing $\mathrm{TiC}$ coating is desired only when the oxygen content of LBE is strictly controlled on a low level.
\end{abstract}

Keywords: SIMP steel; TiC coating; LBE; Self-growing

\section{Introduction}

The accelerator driven sub-critical system (ADS) for energy production and destruction of long-life actinides by transmutation is a promising concept [1]. Liquid LBE (Pb-55.5wt.\% Bi) has been regarded as a candidate for both the target material and the coolant because of the advantages such as low melting point $\left(125^{\circ} \mathrm{C}\right)$, high atomic number, low vapor pressure, good 
neutron yield, fast heat removal and no structural damage from irradiation $[2,3]$. However, the liquid metal can be corrosive towards the structural material. Therefore, it is essential that corrosion is considered when selecting the structural material $[4,5]$.

SIMP steel has been designed as a structural material for ADS, based on the compositions of 9-12Cr heat resistant steels $[6,7]$. The Si content in SIMP steel is around 1.2\% as a compromise between microstructure requirement and corrosion resistance to LBE. However, the decarburization is increased in SIMP steel owing to the carbon-elimination effect of Si. This issue, relevant to ferritic/martensitic steels in general, has not been addressed, in spite of many papers on the subject of oxidation behavior of ferritic/martensitic steels in lead-bismuth eutectic, including some recent ones [8,9]. Fortunately, ceramic coatings such as $\mathrm{TiC}, \mathrm{ZrC}$, $\mathrm{SiC}, \mathrm{Si}_{3} \mathrm{~N}_{4}$ and TiN have been reported to be effective in retarding the corrosion by LBE [1013]. If the eliminated carbon can combine with titanium, a self-growing TiC coating will be formed on the surface of SIMP steel.

Based on this idea, the present research prepared a self-growing TiC coating on the surface of SIMP steel and then evaluated its resistance to $\mathrm{LBE}$ at $600{ }^{\circ} \mathrm{C}$ in both the oxygen saturated and the argon sealed environments.

\section{Experimental}

The composition of the SIMP steel is given in Table 1, where the Si content is as high as $1.43 \%$. The heat treatment for the experimental SIMP steel included normalizing at $1050{ }^{\circ} \mathrm{C}$ for $0.5 \mathrm{~h}$, air cooling to room temperature, and then tempering at $760{ }^{\circ} \mathrm{C}$ for $1.5 \mathrm{~h}$, and finally air cooling to room temperature. This heat treatment process produces a microstructure of tempered martensite and $\mathrm{Cr}_{23} \mathrm{C}_{6}$ precipitates distributed along the lath and the prior austenite grain boundaries [14]. 
Table 1. Chemical composition of the experimental SIMP steel, in wt.\%.

\begin{tabular}{llllllllll}
\hline $\mathrm{C}$ & $\mathrm{Si}$ & $\mathrm{Cr}$ & $\mathrm{Mn}$ & $\mathrm{W}$ & $\mathrm{Ta}$ & $\mathrm{V}$ & $\mathrm{Nb}$ & $\mathrm{S}$ & $\mathrm{P}$ \\
\hline 0.25 & 1.43 & 10.8 & 0.54 & 1.2 & 0.11 & 0.19 & 0.01 & 0.001 & 0.004 \\
\hline
\end{tabular}

Since the decarburization happens mainly during normalizing, the Ti coating should be deposited on the surface of the SIMP steel before heat treatment. Arc ion plating (AIP) was employed to deposit pure $\mathrm{Ti}$ on the surface of the SIMP steel. The steel samples were mechanically polished before $\mathrm{Ti}$ deposition. They had a mirror finish, but at a high magnification, the surfaces of the samples can be seen not even. Small amount of Ti deposited on the bumps will present a particle-like feature on the coating surface. Prior to the Ti deposition, the chamber was preheated to $200{ }^{\circ} \mathrm{C}$ and the pressure was kept below $5 \times 10^{-3} \mathrm{~Pa}$. The ion bombardment of argon glow discharge under a negative bias voltage of $800 \mathrm{~V}$ was then carried out for $10 \mathrm{~min}$ in order to remove metal oxides and other contamination on the surface. During Ar bombardment, the sample was heated up to a temperature of about $300{ }^{\circ} \mathrm{C}$. After the pre-sputtering, the chamber was purged with argon gas. Then, the bias voltage was switched to $-200 \mathrm{~V}$ and the arc current was adjusted to $100 \mathrm{~A}$. The deposition duration for Ti films was 90 min. After the deposition of Ti film, the samples were sealed in a small quartz tube filled with argon to protect from oxygen and then heat treated in a furnace.

X-ray diffraction (XRD) was employed to identify the substance on the surface of the experimental SIMP steel after each treating process. The samples with the TiC coating were put into static $\mathrm{LBE}$ at $600{ }^{\circ} \mathrm{C}$ under two conditions. One is the oxygen saturated LBE sealed in a quartz glass tube, and the other is the LBE sealed in a quartz tube filled with argon. The purity of argon is $99.999 \%$ and the $\mathrm{O}$ content in the argon is below $0.001 \%$. The effect of the oxygen content in the Ar was not considered in the work. The oxygen concentration $c_{\mathrm{O}}$ (wt.\%) in the oxygen saturated case was calculated to be $2.0 \times 10^{-3} \mathrm{wt} . \%$ according to the equation:

$$
\log c_{\mathrm{O}}=1.2-3400 / T
$$


where $T$ is the temperature $(\mathrm{K})[15]$.

After being removed from the liquid LBE, the samples were put into the glycerinum at $150{ }^{\circ} \mathrm{C}$ for 10 min to cleanse away the LBE residuals on the surface. The glycerinum was not stirred and the samples were just placed in it. The samples then were cleansed again by ultrasonic cleaning in acetone. The corrosion products were not removed during the cleaning stages. The residual LBE was dissolved and taken away from the surface of the samples but not the corrosion products. The samples for the observation of the oxide cross section was mounted in resin at room temperature and then ground and polished by following standard metallographic procedures until a mirror polished surface was produced. The cross sectional morphology was observed under a scanning electron microscope (SEM). Electron probe map analysis (EPMA) was employed to show the element distribution in the coatings.

\section{Results}

\subsection{Formation of the $\mathrm{TiC}$ coating}

The XRD results after each process are shown in Fig. 1. The as-rolled steel shows a typical set of peaks of the cubic iron. After Ti deposition, there is a set of stronger peaks of Ti together with the steel substrate peaks. After heat treatment, the peaks of Ti disappear while a set of peaks of TiC emerges, which shows that the desired TiC coating was successfully obtained on the experimental SIMP steel surface through the above processes. It may be noted in Fig. 1 that the Fe peaks in the XRD pattern after heat treatment are much higher than after Ti deposition. The thickness of the Ti-layer is however smaller than the TiC-layer (see Sect. 3.1.1). There are some explanations for this. Firstly, the TiC coating has a different absorption coefficient of Xray from the Ti coating. Secondly, the density of them is different. These factors have bigger effects than thickness of the coatings in absorbing X-ray. Therefore, the thickness of the coatings alone is not sufficient to evaluate the Fe peaks in those two conditions. 


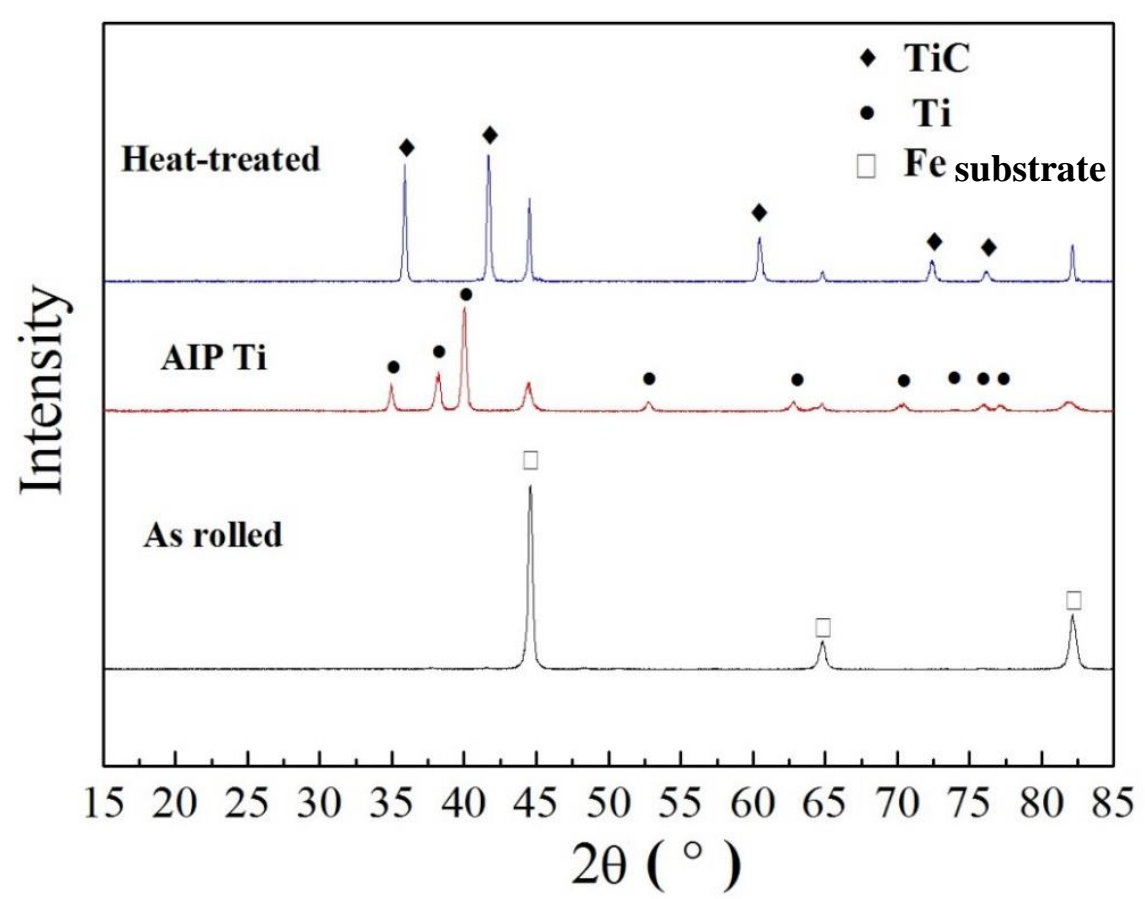

Fig. 1. X-ray diffraction patterns of SIMP steel after rolling, arc ion plating (AIP) of Ti and heat-treatment.

\subsubsection{Morphology development}

Fig. 2 presents the surface and the cross-section morphology of the Ti coating deposited by AIP. During deposition, the temperature of the substrate was around $200{ }^{\circ} \mathrm{C}$, which is too low to generate decarburization layer. The thickness of the Ti coating is about $4.6 \mu \mathrm{m}$. The surface of the Ti coating seems to consist of a large number of small particles, as shown in Fig. 2a. However, when it is observed in the cross section, the coating is crack-free, dense and well attached to the substrate. The particle-like feature in Fig. 2a is from those small bumps on the surface of the Ti coating in Fig. 2b. These small particle features can to some extent obscure the inhomogeneous size of the Ti drops when deposited on the surface. Additionally, the rough surface of the steel can also lead to bumps on the surface, according to the morphology in Fig. 2b. Fig. $2 b$ also indicates that the Ti coating has good adhesion to the substrate, which would benefit the bonding of $\mathrm{TiC}$ coating. There are no voids at the coating/substrate interface. 


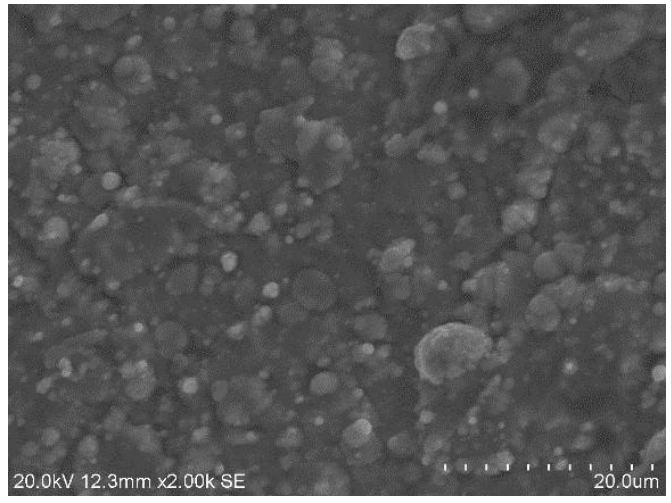

(a)

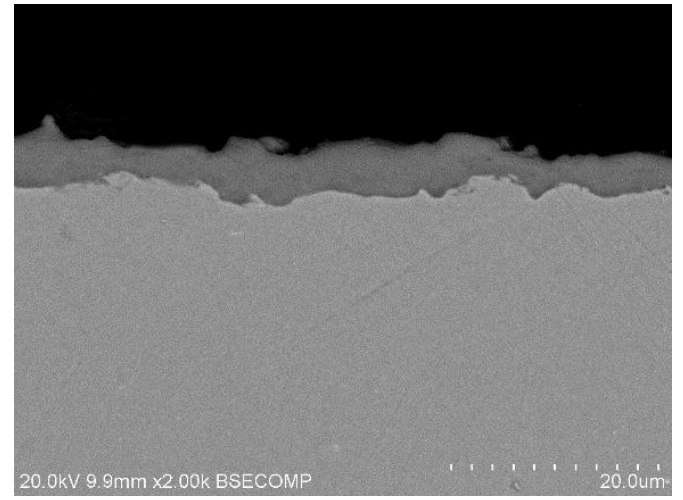

(b)

Fig. 2. Morphology of the deposited Ti coating. (a) Surface; (b) cross-section. The two micrographs have a same magnification, which is different from the magnification of Fig. 3 .

The morphology of the TiC coating formed during normalizing in a quartz tube filled with argon is displayed in Fig. 3. It appears that the surface of the TiC coating is composed of two typical regions. One is the zones containing many particles, for example in the area marked with A in Fig. 3a. The particles are larger than those on the surface of the Ti coating. In other areas, the particles are (partially) fused together, for example in the area marked with B. The formation mechanism of those two different morphologies is not clear. However, from the cross-section morphology, it can be seen that the entire coating is well attached. The space between particles in Fig. 3a can be seen as grooves in Fig. 3b, as indicated by arrows.

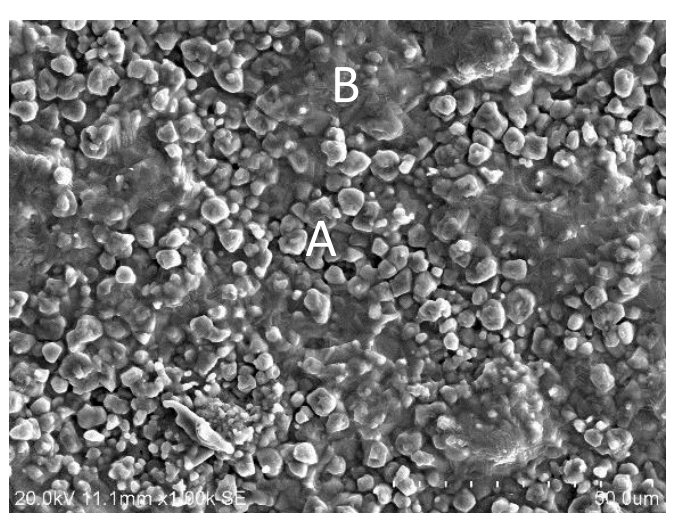

(a)

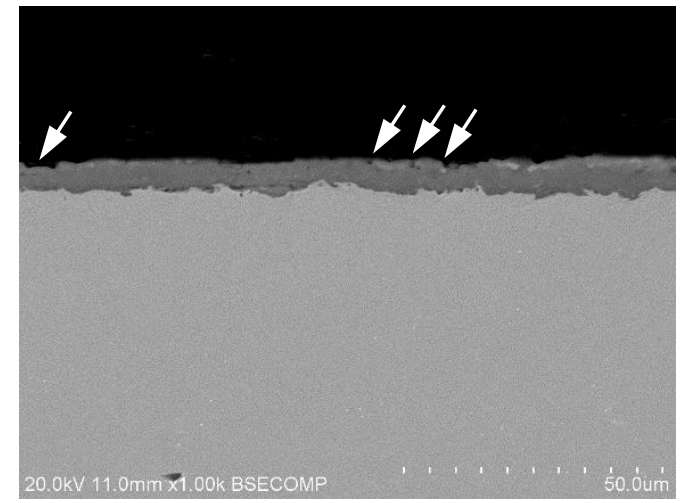

(b)

Fig. 3. Morphology of the TiC coating. (a) Surface; (b) cross-section. The two micrographs have a same magnification, which is different from the magnification of Fig. 2. 
The thickness of the TiC coating is around $5.1 \mu \mathrm{m}$. Compared with the Ti coating, the TiC coating has slight increase in thickness, which should be related to the incorporation of carbon. It may be noted that the density of $\mathrm{TiC}$ is $4.93 \mathrm{~g} / \mathrm{cm}^{3}$ while that of $\mathrm{Ti}$ is $4.5 \mathrm{~g} / \mathrm{cm}^{3}$. Therefore, the approximate mass increase from the Ti to TiC layers is $(5.1 \times 4.93) /(4.6 \times 4.5)-100 \%=21 \%$. This matches perfectly the stoichiometry of $\mathrm{TiC}$, considering the atomic mass of $\mathrm{Ti}$ and $\mathrm{C}$. The element distributions of carbon and titanium are shown in Fig. 4, which indicates the TiC layer.

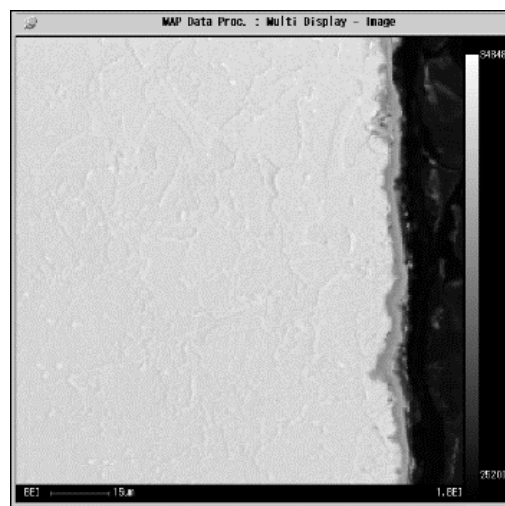

(a)

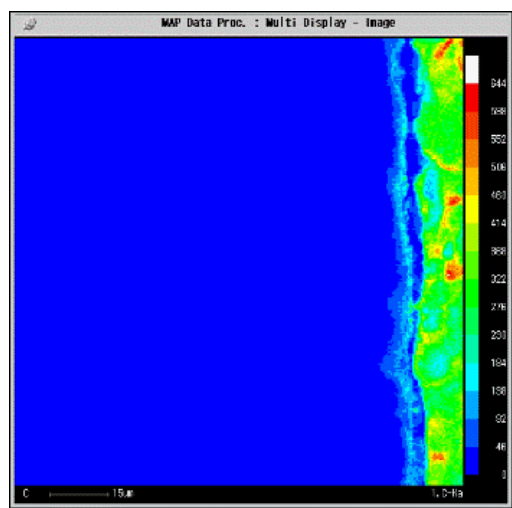

(b)

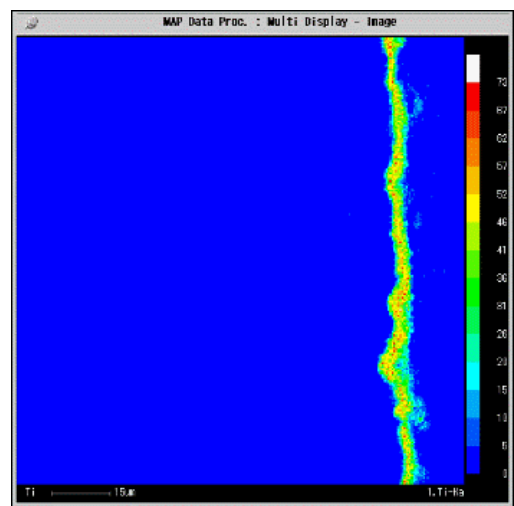

(c)

Fig. 4. EPMA images of TiC layers obtained on SIMP steel after heat-treatment. (a) Backscattered electron image; (b) C; (c) Ti. The length of the scale bars is $15 \mu \mathrm{m}$.

\subsubsection{Decarburization}

Due to the decarburization, the martensitic microstructure near the surface turns into ferrite, as shown in Fig. 5. The decarburization layer is as thick as $0.18 \mathrm{~mm}$. The depletion of carbon during normalizing results in ferritic instead of martensitic microstructure in the near surface substrate steel. The ferritic microstructure is shown in Fig. 5b. It should be pointed out that the boundary like lines, as indicated by the arrows, are probably not grain boundaries, but some small ferrite grains. This microstructure is quite complicated and further work will be carried out to clearly identify the microstructural components. 
If no carbon leaks into the sealed atmosphere, it will be acceptable that the lost carbon in the decarburization layer should be the very carbon combined with titanium. However, the wall of the sealed quartz tube was found to become black, which means that some of the carbon can penetrate through the $\mathrm{Ti} / \mathrm{TiC}$ coating and leave the bulk material. This also helps understand the reason why the decarburization layer is so thick for such a thin layer of $\mathrm{TiC}$ coating. Furthermore, because of the penetration of the carbon through the Ti/TiC coating, an entire layer of TiC coating was generated. Otherwise, the coating after normalizing would have consisted of a very thin layer of $\mathrm{TiC}$ and a Ti coating, almost unchanged from before the heat treatment. The TiC layer cannot be formed through the inward diffusion of Ti alone. Without decarburization, there would be no sufficient supply of carbon to form pure TiC. Without decarburization, Ti diffusing inward, into $\mathrm{Fe}-\mathrm{C}$, might result in $\mathrm{TiC}$ particles in a $\mathrm{Fe}$ matrix, which is not observed here.

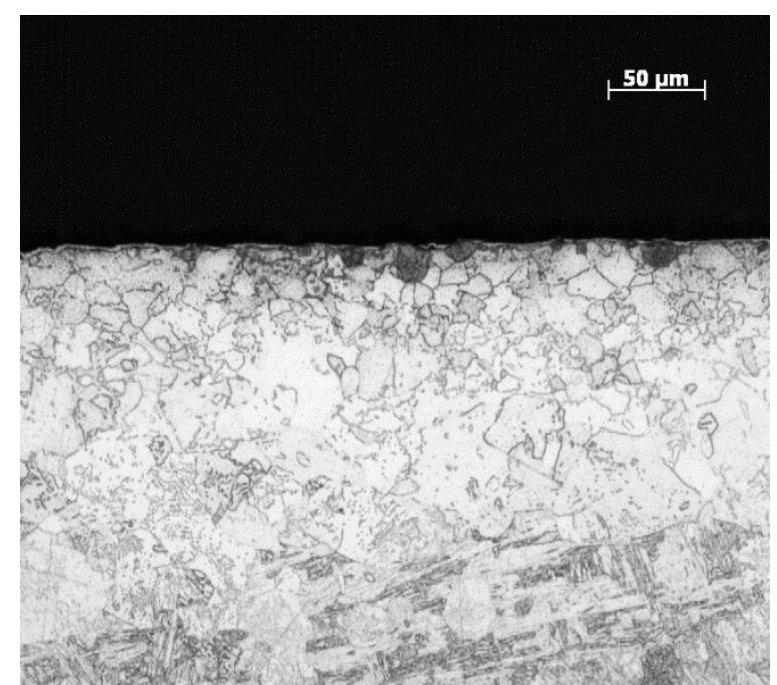

(a)

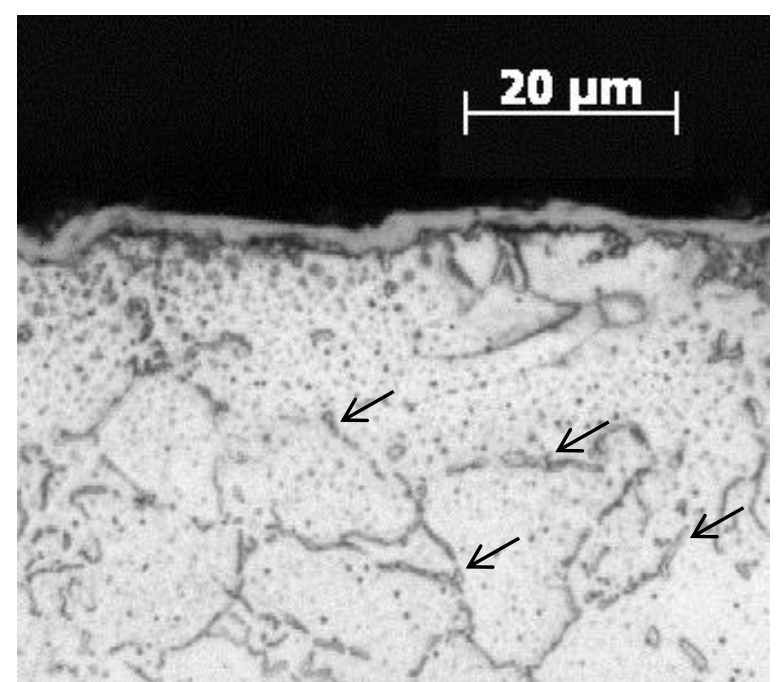

(b)

Fig. 5. Decarburization after normalizing. Coated specimen.

\section{2. $\mathrm{TiC}$ coating in $\mathrm{LBE}$}

\subsubsection{Low oxygen LBE}


The TiC coating is evaluated after keeping in the low oxygen $\mathrm{LBE}$ at $600{ }^{\circ} \mathrm{C}$ for $500 \mathrm{~h}, 1000 \mathrm{~h}$ and 2000 h. The surface morphology of those samples is shown in Fig. 6, with the cross-section morphology in Fig. 7.

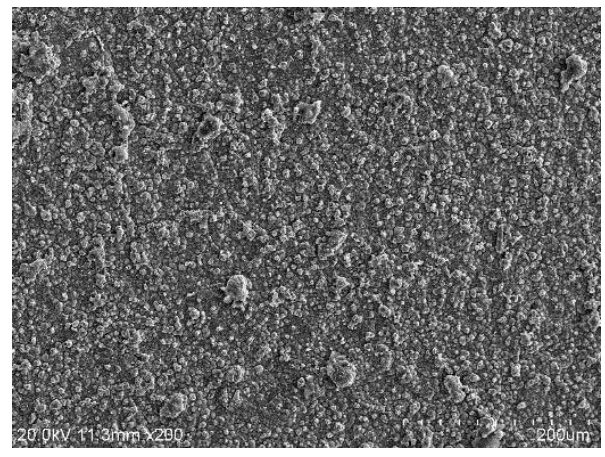

(a)

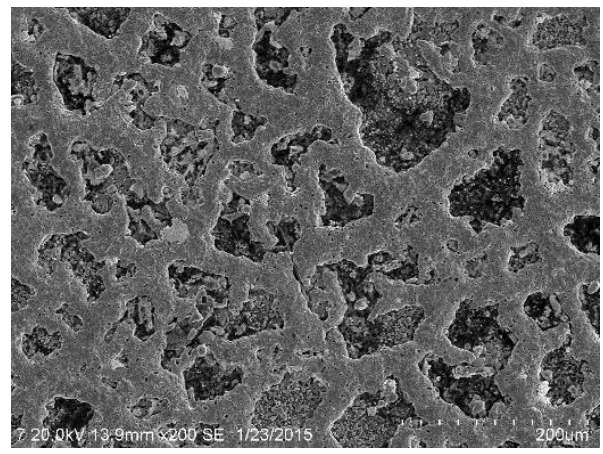

(c)

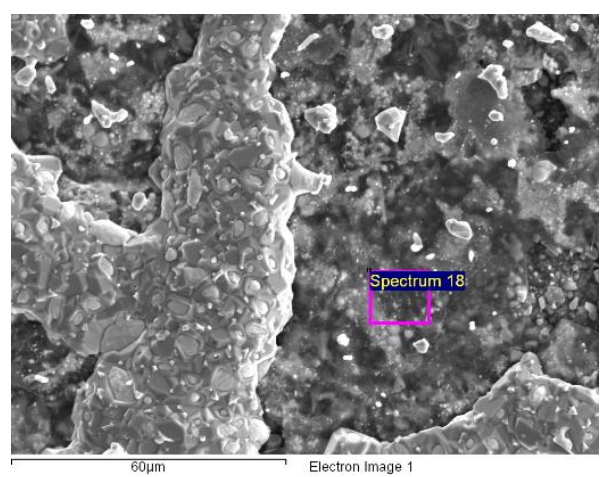

(e)

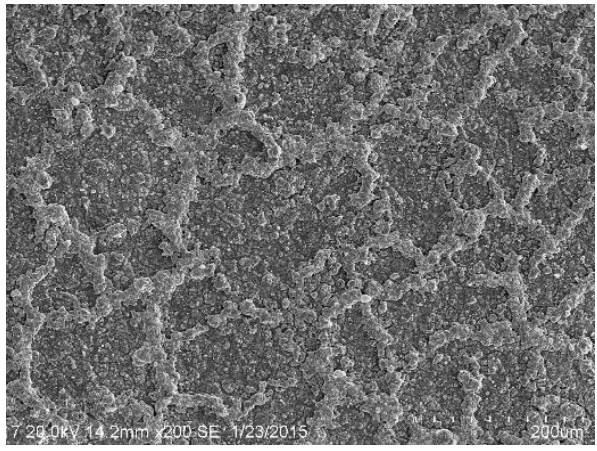

(b)

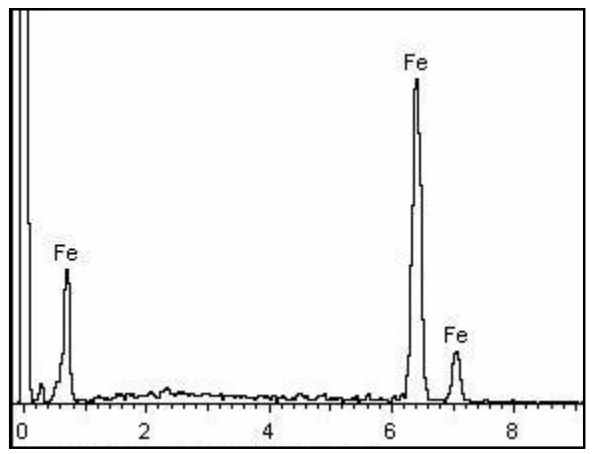

(d)

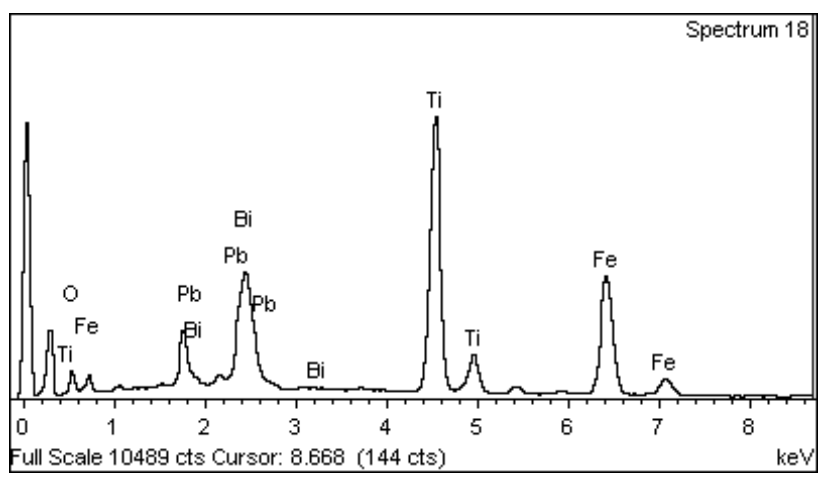

(f)

Fig. 6. Surface morphology of TiC coating after exposure in the low oxygen LBE for (a) 500 h, (b) $1000 \mathrm{~h}$ and (c,e) $2000 \mathrm{~h}$. (d) EDX of (c). (f) EDX of the selected area in (e). The three micrographs in (a), (b) and (c) have a same magnification. 


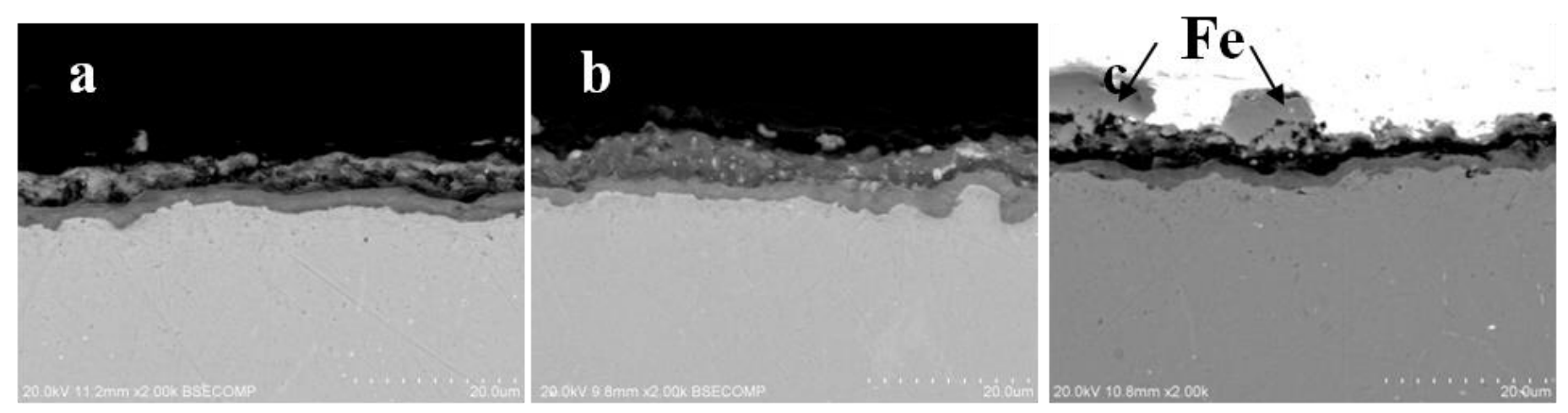

Fig. 7. Cross-section morphology of TiC coating after exposure in the low oxygen LBE for (a) $500 \mathrm{~h}$, (b) $1000 \mathrm{~h}$ and (c) $2000 \mathrm{~h}$. 
After being exposed in the low oxygen LBE at $600{ }^{\circ} \mathrm{C}$ for $500 \mathrm{~h}$, it is identified by XRD that a surface oxide scale or layer of $\mathrm{FeTiO}_{3}$ forms on the steel, as shown in Fig. 8. However, with time increasing, there is another mesh-like film formed on the surface of the $\mathrm{FeTiO}_{3}$ oxide scale or layer. This mesh-like film is revealed by EDX to be just iron (Fig. 6d). The EDX of the area in between is given in Figs. 6e and 6f, showing mainly Fe and Ti oxide. The composition (wt.\%) obtained from Fig. of is $11.2 \% \mathrm{O}, 35.7 \% \mathrm{Ti}, 28.5 \% \mathrm{Fe}, 10.5 \% \mathrm{~Pb}, 14.2 \% \mathrm{Bi}$. Therefore, it is suspected that this iron will not be present in a great amount if the exposure duration is not long enough, so the mesh-like iron could not be observed when the sample was exposed in the low oxygen $\mathrm{LBE}$ at $600{ }^{\circ} \mathrm{C}$ for $500 \mathrm{~h}$. When the exposure duration is increased to $1000 \mathrm{~h}$, the mesh-like iron appears. This iron film grows larger with increasing exposure duration, to possibly eventually cover the entire surface.

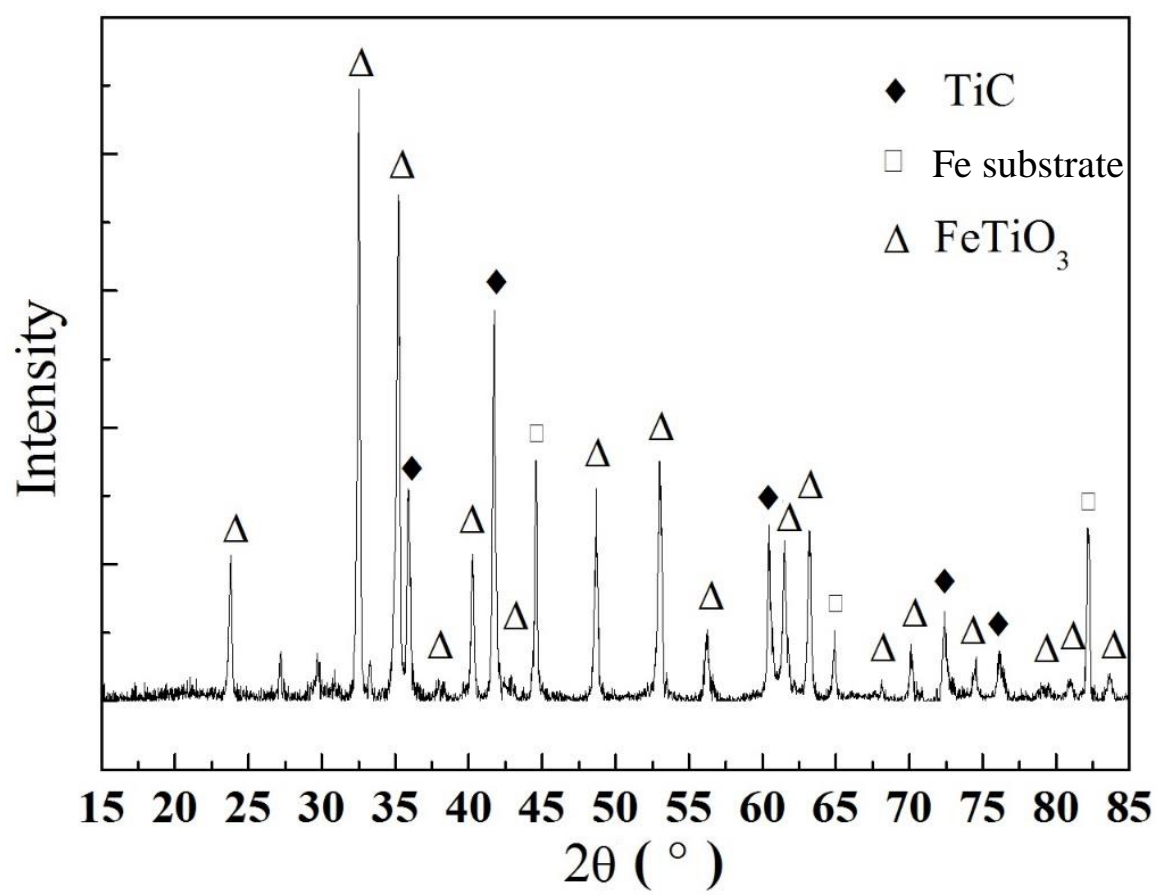

Fig. 8. X-ray diffraction pattern of the coating after exposure in the low oxygen LBE at $600{ }^{\circ} \mathrm{C}$ for $500 \mathrm{~h}$.

It is illustrated in Fig. 7 that the TiC coating can effectively protect the steel from the corrosion by LBE under this condition. However, the thickness of the TiC coating was measured to be 2.26, 1.92 and $1.86 \mu \mathrm{m}$ after being kept in the oxygen-isolated LBE for 500, 1000 and $2000 \mathrm{~h}$, 
respectively. It appears that the $\mathrm{TiC}$ coating loses its thickness with increasing length of time in LBE. It is also worth noticing that the thickness is reduced rapidly in the first $500 \mathrm{~h}$, and then the decreasing rate slows down.

It is also demonstrated by EPMA that the TiC coating can strongly prevent $\mathrm{Pb}$ from penetrating (Fig. 9). In Figs. 9f and 9g, $\mathrm{Pb}$ and $\mathrm{Bi}$ are stopped right outside of the surface of TiC coating. Careful examination and comparison of the images in Fig. 9 shows that $\mathrm{Pb}$ is not at the coating/substrate interface, but is outside the coating surface. As shown in Fig. 9a, the cross section specimen has preparation defects outside the coating surface, due to the loose LBE there. The EPMA analysis over such uneven part of the specimen can only be used in a qualitative way. It is also worth noticing that $\mathrm{C}$ and $\mathrm{Ti}$ are both revealed to segregate toward the outer layer of the coating, illustrated in Figs. 9c and 9e, respectively, by the yellow zone and the red zone, respectively. The distribution of $\mathrm{Cr}$ in the subsurface zone is even (not included in Fig. 9). Cr is in solid solution in the substrate. Evidently, Fig. 9 is an analysis of a mesh area. Fe is detected at the surface of TiC coating as Fig. 9b shows. However, the apparently low Fe concentration at the surface of TiC coating exhibited in Fig. 9b should not be taken as a quantitative measurement, due to the spatial resolution of the EPMA, of the order of $1 \mu \mathrm{m}$, and the surface effect which will lead to even lower spatial resolution comparing to analysis of a bulk area. For the same reason, the gradual, sub-micron scale changes in contrast in all EPMA and backscattered electron images should not be regarded as real graduate changes in composition. The EPMA analysis of the light element $\mathrm{C}$ is much less accurate than for metallic elements. We do not have a conclusive measurement on whether the $\mathrm{C}$ content is the same after $2000 \mathrm{~h}$ of exposure in low oxygen LBE as after TiC formation.

Although the atmosphere was oxygen controlled, the oxygen in the $\mathrm{Pb}-\mathrm{Bi}$ eutectic alloy could not be controlled. However, by comparing the maps, it could be seen that the oxygen was combined with $\mathrm{Pb}, \mathrm{Bi}$ and the external $\mathrm{Fe}$, which formed actually $\mathrm{FeTiO}_{3}$ with $\mathrm{Pb}$ and $\mathrm{Bi}$ dissolved as shown by the XRD in Fig. 8. 


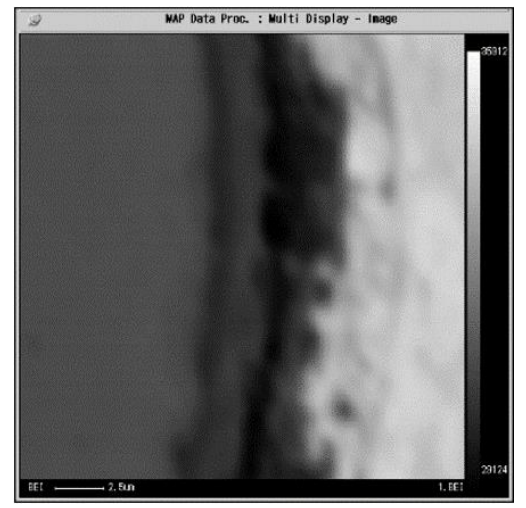

(a)

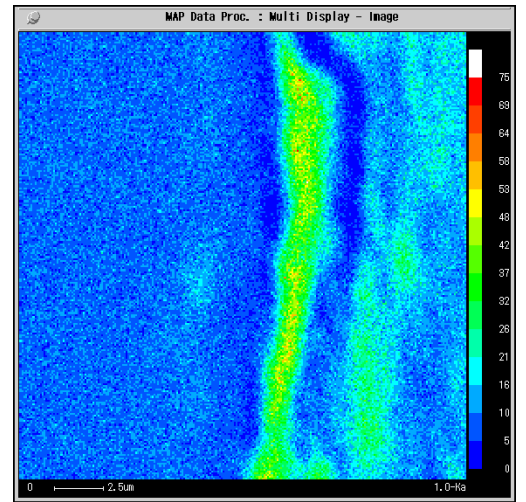

(d)

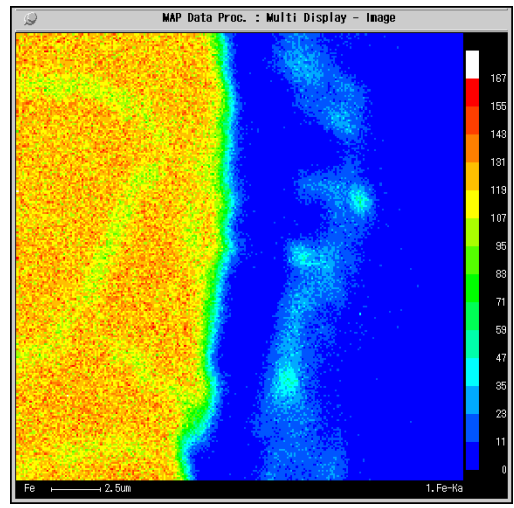

(b)

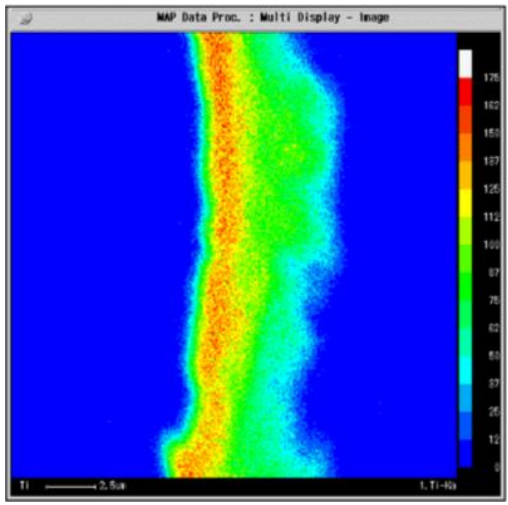

(e)

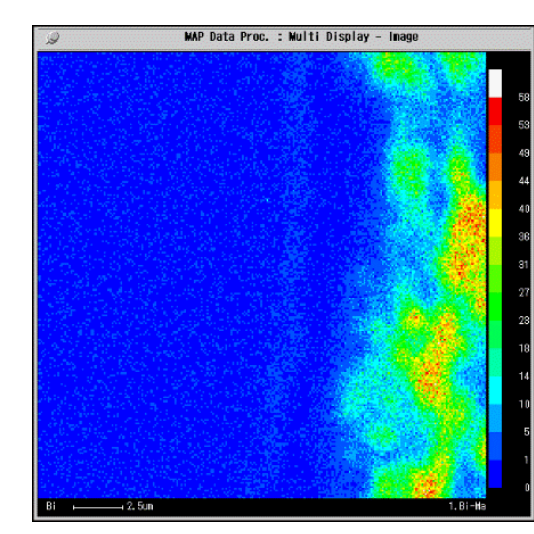

(g)

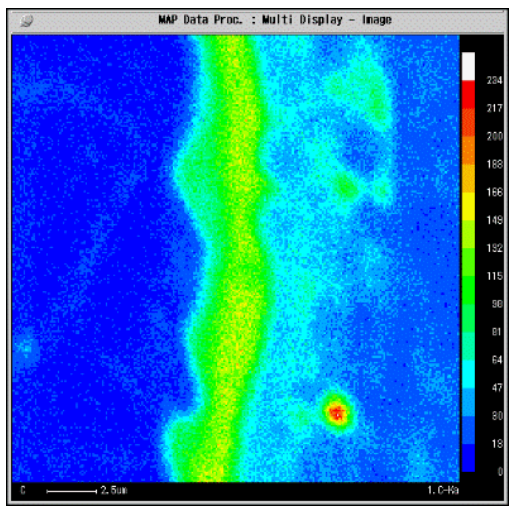

(c)

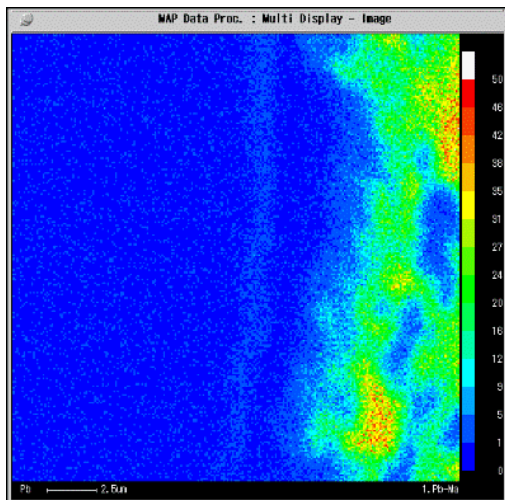

(f) 


\subsubsection{Oxygen saturated LBE}

After the TiC coating was immersed in the oxygen saturated LBE, totally different results were obtained. Fig. 10 presents the backscattered SEM images of the morphology of the cross section. The XRD result in Fig. 11 shows that, after exposure in oxygen-saturated static liquid $\mathrm{LBE}$ at $600{ }^{\circ} \mathrm{C}$ for $500 \mathrm{~h}$, the $\mathrm{TiC}$ coating is transformed into two other oxides, namely $\mathrm{TiO}_{2}$ and $\mathrm{PbTiO}_{3}$. The outer bright layer in Fig. 10 is the $\mathrm{PbTiO}_{3}$ layer and the dark inside layer below the $\mathrm{PbTiO}_{3}$ layer in Fig. 10a is $\mathrm{TiO}_{2}$, as demonstrated by the EPMA results in Fig. 12 .

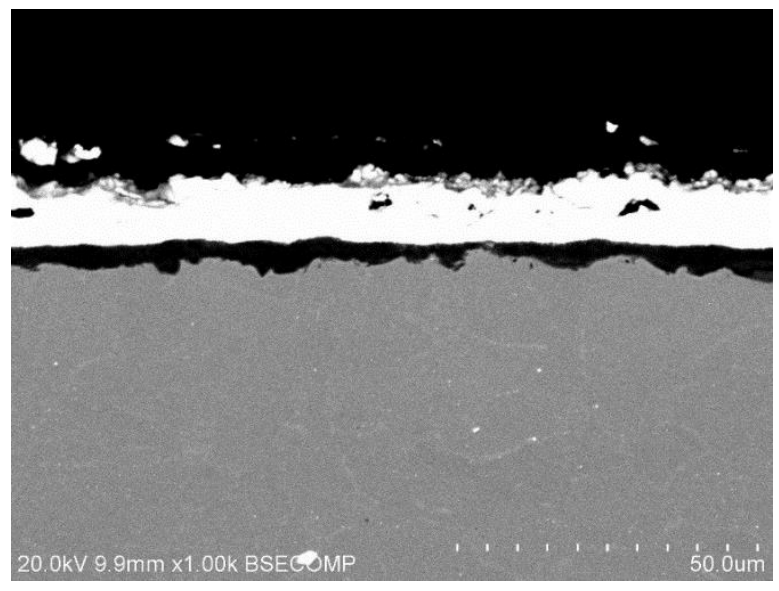

(a)

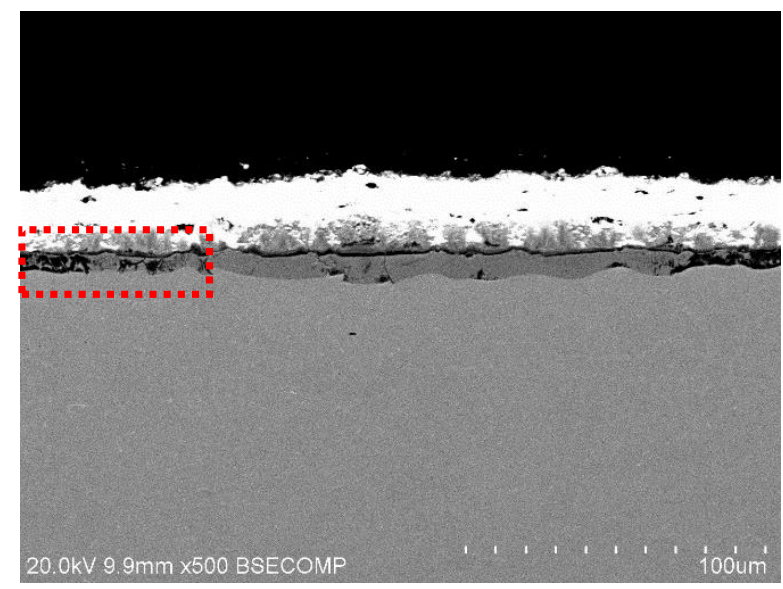

(b)

Fig. 10. SEM images showing the cross section morphology of the TiC coating after exposure in the oxygen saturated $\mathrm{LBE}$ at $600{ }^{\circ} \mathrm{C}$ for $500 \mathrm{~h}$. (a) Dark inside $\mathrm{TiO}_{2}$ layer below the outer bright $\mathrm{PbTiO}_{3}$ layer; (b) gray Fe-rich layer as the internal layer, also containing $\mathrm{Ti}$ and $\mathrm{O}$.

Therefore, the $\mathrm{TiC}$ coating was soon oxidized into $\mathrm{TiO}_{2}$ and the $\mathrm{TiC}$ coating cannot protect the steel from the corrosion by the oxygen saturated LBE at $600{ }^{\circ} \mathrm{C}$. However, in Fig. 10b, instead of the dark $\mathrm{TiO}_{2}$ layer, a section of gray layer is observed to be the internal layer. This gray layer was found to be Fe-rich, in addition to $\mathrm{Ti}$ and $\mathrm{O}$. Therefore, it is plausible that the $\mathrm{TiO}_{2}$ layer gradually evolved into the $\mathrm{FeTiO}_{3}$ due to the diffusion of Fe outward. As marked by the red rectangle, the dark area is turning gray. However, whether this gray layer is effective in 
stopping the oxidation by the oxygen saturated LBE is not known, yet. In conclusion, the TiC coating cannot protect the steel in the oxygen saturated LBE.

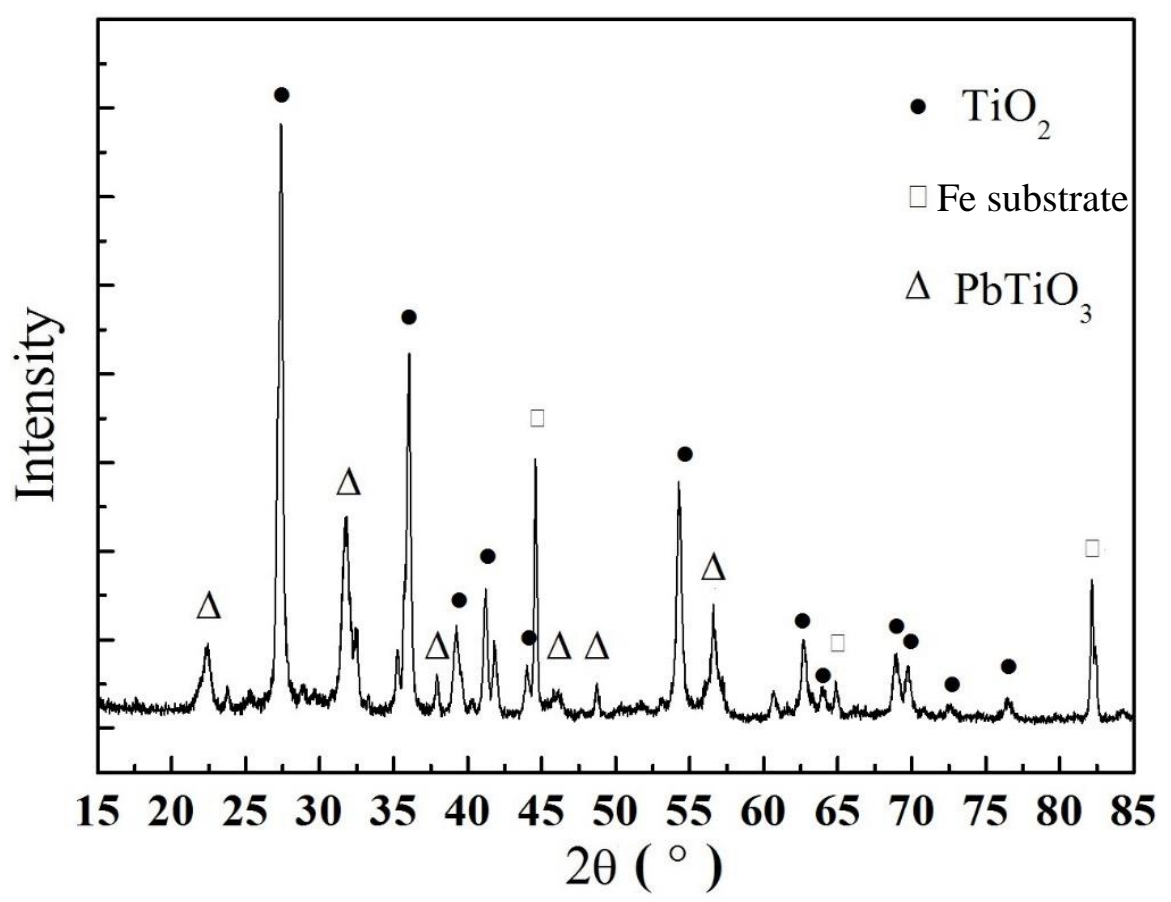

Fig. 11. X-ray diffraction pattern of the coating after exposure in the oxygen saturated LBE at $600{ }^{\circ} \mathrm{C}$ for $500 \mathrm{~h}$.

\section{Discussion}

\subsection{Corrosion in the low oxygen LBE}

The first layer outside of the $\mathrm{TiC}$ coating is the layer of $\mathrm{FeTiO}_{3}$ which can be represented as $\mathrm{FeO} \cdot \mathrm{TiO}_{2}$, and then with the increase of exposure duration, the mesh-like iron is observed, as shown in Figs. 6 and 7. Since the oxygen content in the quartz tube was so low and there is no $\mathrm{PbTiO}_{3}$ observed, it is reasonable to believe that oxygen exists in the form of atom [O] instead of $[\mathrm{Pb}-\mathrm{O}]$ clusters [16]. The probable oxidation reaction in atom [O] dissolved LBE is expressed as follows:

$\mathrm{TiC}+2[\mathrm{O}] \rightarrow \mathrm{TiO}_{2}+\mathrm{C}$ 
Here, the Gibbs energy for the reaction $\Delta_{r} G_{e q .(2)}(\mathrm{J} / \mathrm{mol})$ of Eq. (2) is:

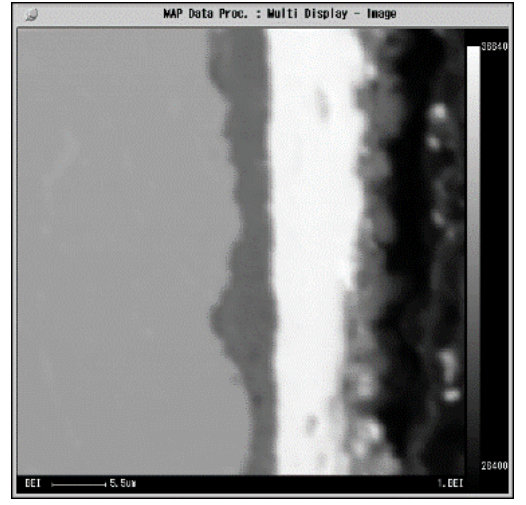

(a)

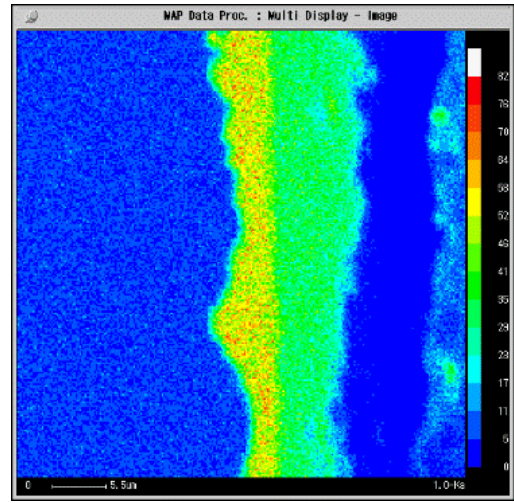

(b)

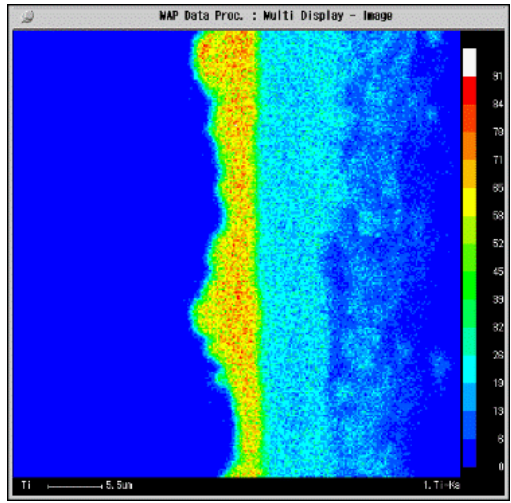

(c)

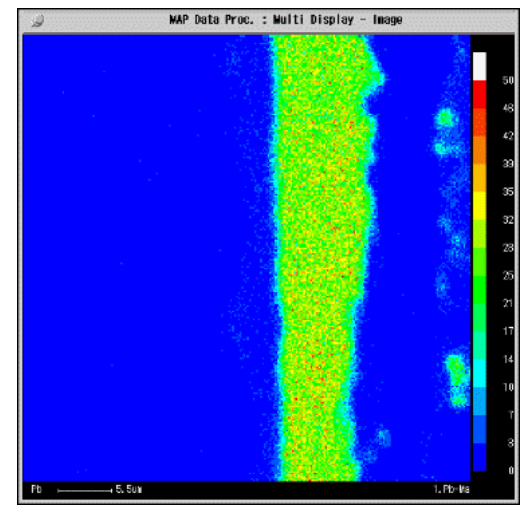

(d)

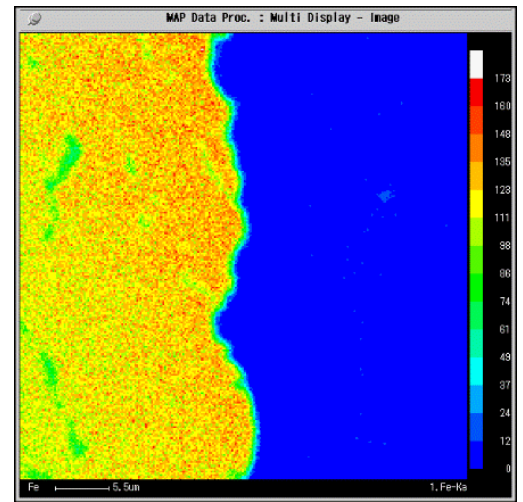

(e)

Fig. 12. EPMA images of TiC coating after exposure in the oxygen saturated $\mathrm{LBE}$ at $600{ }^{\circ} \mathrm{C}$ for 500 h. (a) Backscattered electron image; (b) O; (c) Ti; (d) Pb; (e) Fe. The length of the scale bars is $5.5 \mu \mathrm{m}$.

$\Delta_{r} \mathrm{G}_{e q \cdot(2)}=\Delta_{r} \mathrm{G}_{e q \cdot(2)}^{0}+R T \ln \frac{C_{T i O_{2}} C_{C}}{C_{T i C} C_{[0]}^{2}}$

where $\Delta_{r} G_{e q .(2)}^{0}$ is the Gibbs reaction energy $(\mathrm{J} / \mathrm{mol})$ for standard state for Eq. (2), estimated as $-612 \mathrm{~kJ} / \mathrm{mol}$ at $600{ }^{\circ} \mathrm{C}$ [17], $R$ is the gas constant $\left(8.314 \mathrm{~J} \mathrm{~K}^{-1} \mathrm{~mol}^{-1}\right), c$ is concentration (mol/l). Given $\Delta_{r} \mathrm{G}_{e q .(2)}=0$, the equilibrium oxygen concentration is calculated to be $8.0 \times 10^{-18}$ wt. $\%$. This calculated result indicates that if there is oxygen, even if very little, the $\mathrm{TiC}$ coating will be oxidized into $\mathrm{TiO}_{2}$. However, this reaction cannot explain the formation of 
the $\mathrm{FeTiO}_{3}$ layer. A source of iron is needed. The iron in the steel is covered by the TiC coating. The Fe map of the EPMA given in Fig. 9b shows the TiC layer preventing Fe diffusion. Therefore, iron must come from another resource. Experimentally, in order to make the samples immersed in the LBE, iron wires were used to fix them. Therefore, the wires will provide iron. At first, the iron was oxidized into $\mathrm{FeO}$, which should be related to the formation of the $\mathrm{FeTiO}_{3}$ layer. When the oxygen ran out, the iron will directly dissolve into LBE [18, 19], which is the so-called dissolution corrosion by LBE. The LBE cannot accommodate much iron; the solubility of iron in $\mathrm{LBE}$ at $600{ }^{\circ} \mathrm{C}$ is calculated to be $9.9 \times 10^{-4}$ in wt.\% according to the equation [15]:

$\log c_{\mathrm{Fe}}=2.01-4380 / T$

Therefore, the quickly saturated iron would then nucleate and precipitate again on the coating surface. This speculation seems to properly explain the observation of the delayed mesh-like iron in Figs. 6 and 7. The thickness evolution of the TiC coating is in accordance with the oxidation process and can be well understood considering the consumption of oxygen in the quartz tube. It may be noted however that Fe was not observed on other parts of the equipment.

\subsection{Oxidation corrosion in the oxygen saturated LBE}

In the oxygen saturated LBE, the TiC coating was promptly and completely oxidized into the porous $\mathrm{TiO}_{2}$ and $\mathrm{PbTiO}_{3}$ which can also be presented as $\mathrm{PbO} \cdot \mathrm{TiO}_{2}$, as shown in Fig. 10. The high oxygen activity $\left(\alpha_{O}=1\right)$ due to the high temperature of $600{ }^{\circ} \mathrm{C}$ and the saturated state strongly support the belief that the oxygen is present in the form of [Pb-O] clusters [16] in the static oxygen-saturated liquid LBE. The probable oxidation reaction in the oxygen saturated LBE can be expressed as follows:

$\mathrm{TiC}+2 \mathrm{PbO} \rightarrow \mathrm{TiO}_{2}+2 \mathrm{~Pb}+\mathrm{C}$ 
where the Gibbs formation energy of $\mathrm{TiC}, \mathrm{PbO}$ and $\mathrm{TiO}_{2}$ can be expressed as:

$\Delta_{f} \mathrm{G}_{m}^{\theta}=A+B T$

The values and units of $A$ and $B$ are listed in Table 2. Here, the Gibbs reaction energy for the reaction of Eq. (5) is:

$\Delta_{r} \mathrm{G}_{e q .(5)}=\Delta_{r} \mathrm{G}_{e q .(5)}^{0}+R T \ln \frac{C_{T i O_{2}} C_{P b}^{2} C_{C}}{C_{T i C} C_{P b o}^{2}}$

where $\Delta_{r} G_{e q .(5)}^{0}$ is the Gibbs reaction energy for standard state for Eq. (5) and it is estimated at $-350 \mathrm{~kJ} / \mathrm{mol}$ at $600{ }^{\circ} \mathrm{C}$ [17]. $\Delta_{r} \mathrm{G}_{\text {eq.(5) }}=-286 \mathrm{~kJ} / \mathrm{mol}$ when the oxygen concentration is $2.0 \times 10^{-3}$ wt. $\%$. This estimate indicates that the oxidation of $\mathrm{TiC}$ into the porous $\mathrm{TiO}_{2}$ in the static LBE saturated with oxygen at $600{ }^{\circ} \mathrm{C}$ is spontaneous. It should be noted that Eq. (5) is a simplified equation according to Ref. [10] and does not consider the formation of $\mathrm{CO}_{2}$ or $\mathrm{CO}$, but the following consideration is given in relation to the potential formation of these gases. The quartz tube was not broken during the tests, and we did not test for the existence of $\mathrm{CO}_{2}$ or CO. The only different behavior between the tests in the oxygen saturated LBE and in the LBE sealed in a quartz tube filled with argon was the $\mathrm{PbO}$ formation on the top of liquid LBE in the former condition.

Table 2. Values of $A$ and $B$ in Gibbs formation energy expressions

\begin{tabular}{llll}
\hline Compound & $A\left(\mathrm{~J} \cdot \mathrm{mol}^{-1}\right)$ & $B\left(\mathrm{~J} \cdot \mathrm{mol}^{-1} \cdot \mathrm{K}^{-1}\right)$ & Temperature range $(\mathrm{K})$ \\
\hline $\mathrm{TiC}$ & 184800 & 12.55 & $298-1943$ \\
$\mathrm{TiO}_{2}$ & 941000 & 177.57 & $298-1943$ \\
$\mathrm{PbO}$ & 219140 & 101.15 & $601-1158$ \\
\hline
\end{tabular}

The $\mathrm{TiO}_{2}$ is porous and cannot prevent iron from diffusing outward and oxygen inward, so the black $\mathrm{TiO}_{2}$ in Fig. 10b is observed to transform into the gray layer gradually. It should be noted 
however that the concentration of $\mathrm{Fe}$ which diffuses through the $\mathrm{TiO}_{2}$ is too low to be detected by EPMA. So, in Fig. 12, no Fe is found within the Ti enriched zone. The iron wires were also used to fix the samples in the oxygen saturated LBE. However, since the oxygen is sufficient, dissolution corrosion by LBE cannot happen, so it is impossible to form the mesh-like iron. Those iron wires will only bring about contamination but do not affect the corrosion of the TiC coating in the oxygen saturated LBE. Using Pt (or other materials) wires to fix the samples could avoid the Fe contamination, which will be attempted in future research.

For further investigations, a treatment of Ni-plating before metallographic preparation to clearly show the outer borders of the scales should be considered.

\section{Conclusion}

In this investigation, the self-grown TiC coating is obtained for SIMP steel, which can effectively protect the steel from the corrosion by the low oxygen LBE, but fails to prevent the corrosion by the oxygen saturated LBE. The main conclusions are as follows:

(1) The self-growing TiC coating can be achieved by making use of the decarburization of SIMP steel.

(2) The self-growing TiC coating can effectively protect SIMP steel from the corrosion by the low oxygen $\mathrm{LBE}$ in the argon charged quartz tube at $600{ }^{\circ} \mathrm{C}$.

(3) The self-growing TiC coating is easily oxidized in the oxygen saturated $\mathrm{LBE}$ at $600{ }^{\circ} \mathrm{C}$ and loses its protection function.

(4) The oxygen content in the liquid LBE is the key to the corrosion at high temperatures. If the self-growing TiC coating is used to protect SIMP steel from the liquid LBE, the oxygen content should be strictly controlled at a low level.

\section{Acknowledgments}


This work was financial supported by the sub-project (XDA03010301, XDA03010302) of Advanced Fission Energy Program-ADS Transmutation System, Chinese Academy of Sciences Strategic Priority Research Program (XDA03010000).

\section{References}

[1] C. Rubbia, J. A. Rubio, S. Buono, F. Carminati, N. Fiétier, J. Galvez, C. Gelès, Y. Kadi, R. Klapisch, P. Mandrillon, J. P. Revol, Ch. Roche, Conceptual Design of A Fast Neutron Operated High Power Energy Amplifier, European Organization for Nuclear Research, Geneva 1995.

[2] F. Barbier, G. Benamati, C. Fazio, A. Rusanov, J. Nucl. Mater. 2001, 295, 149.

[3] C. Fazio, G. Benamati, C. Martini, G. Palombarini, J. Nucl. Mater. 2001, 296, 243.

[4] K. Lambrinou, V. Koch, G. Coen, J. Van den Bosch, C. Schroer, J. Nucl. Mater. 2014, 450, 244.

[5] J. S. Zhang, Corr. Sci. 2009, 51, 1207.

[6] Q. Shi, J. Liu, H. Luan, Z. Yang, W. Wang, W. Yan, Y. Shan, K. Yang, J. Nucl. Mater. 2015, $457,135$.

[7] Q. Shi, J. Liu, W. Wang, W. Yan, Y. Shan, K. Yang, Oxid. Met. 2015, 83, 521.

[8] X. Gong, P. Marmy, B. Verlinden, M. Wevers, M. Seefeldt, Corr. Sci. 2015, 94, 377.

[9] A. M. Bolind, R. S. Lillard, J. F. Stubbins, Corr. Sci. 2015, 92, 48.

[10] M. Takahashi, M. Kondo, Prog. Nucl. Energy 2011, 53, 1061.

[11] I. Kim, F. Khatkhatay, L. Jiao, G. Swadener, J. I. Cole, J. Gan, H. Wang, J. Nucl. Mater. 2012, 429, 143.

[12]E. Yamaki-Irisawa, S. Numata, M. Takahashi, Prog. Nucl. Energy 2011, 53, 1066.

[13]M. Takahashi, S. Uchida, K. Hata, T. Matsuzawa, H. Osada, Y. Kasahara, N. Sawa, Y. Okubo, T. Obara, E. Yusibani, Prog. Nucl. Energy 2005, 47, 190.

[14]R. L. Klueh, D. R. Harries, High-chromium Ferritic and Martensitic Steels for Nuclear Applications, ASTM, West Conshohocken 2001.

[15]B. F. Gromov, Y. I. Orlov, P. N. Martynov, V. A. Gulevsky, presented at Heavy Liquid Metal Coolants in Nuclear Technology, Obninsk, Russia, October 5-9, 1998, pp. 92-107. 
[16] O. Yeliseyeva, V. Tsisar, G. Benamati, Corr. Sci. 2008, 50, 1672.

[17]J. G. Speight, Lange's Handbook of Chemistry, 16th edn., McGraw-Hill Education, New York 2005, pp. 308-309.

[18] I. V. Gorynin, G. P. Karzov, V. G. Markov, V. S. Lavrukhin, V. Ya. Yakovlev, presented at Heavy Liquid Metal Coolants in Nuclear Technology, Obninsk, Russia, October 5-9, 1998, pp. 128-135.

[19] M. Kondo, M. Takahashi, K. Miura, T. Onizawa, J. Nucl. Mater. 2006, 357, 97. 